\title{
Speed Control of the Main Drive System for Alloy Magnesium Sheet Rolling Mill
}

\author{
Fan Li-ping \\ College of Environment and Safety Engineering \\ Shenyang University of Chemical Technology \\ Shenyang, China \\ e-mail: flpsd@163.com
}

\author{
Deng Yong-juan \\ College of Information Engineering \\ Shenyang University of Chemical Technology \\ Shenyang, China \\ e-mail: 760011051@qq.com
}

\begin{abstract}
The main drive system using for four-high rolling mill is usually a double closed-loop DC motor speed regulating system, whose performance influences the product quality directly. In this paper, the model specific parameters required for the main drive system are calculated by the method of engineering design. Then, a double closed-loop speed regulating system is established for the rolling mill. The designed speed control system is tested by the simulation software. Simulation results show that the designed double closed-loop speed regulating system for the main drive system of rolling mill has a good effect on speed controlling.
\end{abstract}

Keywords- main drive system; four-high rolling mill; double closed-loop; engineering design method; speed-control

\section{INTRODUCTION}

Magnesium alloy is by far the lightest metal in structural materials engineering applications in defense, aerospace, high-speed trains, automobiles and electronic communications and other fields. It is known as the most potential "green engineering metal structural materials" in the 21 st century ${ }^{[1-2]}$. With the various sectors of the growing demand for magnesium alloy sheet, magnesium alloy sheet rolling technology is getting more and more important.

$1750 \mathrm{~mm}$ four rolling mill group is a very important device for magnesium plate rolling process, which drives rolls up and down work synchronistically through the main drive system ${ }^{[3]}$. Speed adjustment of the main drive system is the primary attention of the link. In practical applications, for rolling mill main drive speed control, double closed-loop DC speed control system is the most commonly used ${ }^{[4-6]}$. In this paper, based on the specific parameters of $1750 \mathrm{~mm}$ four-high rolling mill, a double loop DC speed control system was designed after analysis and calculation.

\section{Design of the MaIN DRIVE System}

In this paper, engineering design approach is used to design the speed, current double-loop speed regulating system. In accordance with the general principles of designing a multi-loop control system, the system is designed from inner loop to outer loop. For a double closed-loop system, the inner current control is designed first, then the entire current loop is regarded as one part of the speed regulation system, and then outer speed regulator is designed ${ }^{[5]}$. The dynamic block diagram of the double closed-loop speed regulating system is shown in Fig. 1

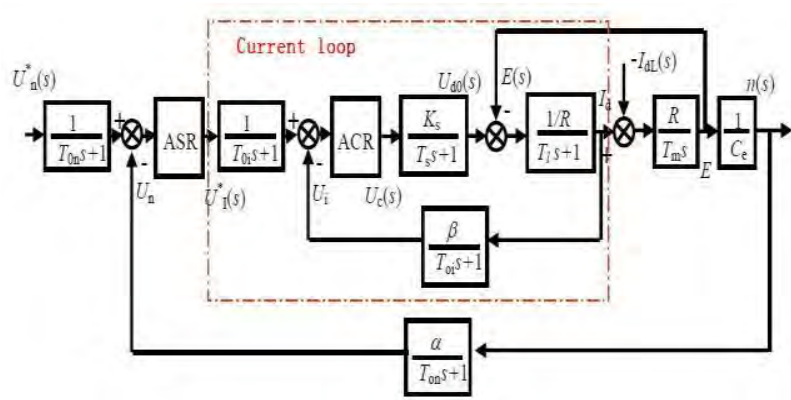

Figure 1. Dynamic block diagram of double closed loop speed control system

The difference with traditional system is that adding filter links, including the current filter, speed filter and two given signal filter links. Current detection signal often contains AC component, in order not to make it affect the regulator input, preceded by a low-pass filter. In order to balance the delay of the feedback signal filtering links, a given filter link with constant equal time is added on the given signal path. Similarly, the speed feedback voltage which is obtained from tachometer generator contains ripple, also need filtering. A given filter link with constant equal time is added on the speed channel ${ }^{[7-11]}$.

\section{A Main Parameters Calculation}

$1750 \mathrm{~mm}$ four-high rolling mill of magnesium alloy uses two identical DC motor as the main drive motor. The double closed-loop DC speed regulating system is used for controlling the upper and lower work roller motor. The main drive motor is chosen as ZD250 / 105. The main parameters of the motor are as follows: the power rating is $2500 \mathrm{~kW}$, the voltage rating is $870 \mathrm{~V}$, the rated current is $3100 \mathrm{~A}$, the armature resistance is $0.01 \Omega$, and the magnetizing inductance is $2.223 \mathrm{H}$, the excitation resistance: $0.8978 \Omega$, the overload multiples is 1.25 , the moment of inertia is $32625 \mathrm{kgm}^{2}$, the rated speed is $50 \mathrm{r} /$ min. According to the above parameters gained by nameplate or test, parameters required for the engineering design can be calculated.

The control voltage $U_{n}^{*}=U_{i}^{*}$ is designed in the range of $0-10 \mathrm{~V}$. The design index of speed overshoot is 
$\delta_{n}=10 \%$

The counter electromotive force of the motor is

$$
\begin{aligned}
C_{e} & =\frac{U_{N}-I_{N} R_{a}}{n_{N}}=\frac{870-3100 \times 0.01}{50} \\
& =16.78 \mathrm{~V} \cdot \mathrm{min} / r
\end{aligned}
$$

The moment coefficient is

$$
C_{m}=\frac{30}{\pi} C_{e}=9.55 \times 16.78=160 \mathrm{~V} . \mathrm{min} / r
$$

The armature current time constant of the motor is

$$
T_{l}=\frac{L_{a}}{R_{a}}=\frac{1.851}{0.01}=0.185 \mathrm{~s}
$$

The electrical and mechanical time constant of electric drive system is

$$
\begin{aligned}
T_{m} & =\frac{G D^{2} R}{375 C_{e} C_{m}}=\frac{4 g J R}{375 C_{e} C_{m}} \\
& =\frac{4 \times 9.81 \times 32625 \times 0.01}{375 \times 16.78 \times 160}=0.0127 \mathrm{~s}
\end{aligned}
$$

\section{B Design of The Double Closed-Loop Speed Regulating System}

According to engineering design methods, the double closed-loop DC speed regulating system controller can be designed to meet the requirements.

The main drive system of the $1750 \mathrm{~mm}$ four-high rolling mill adopts two three-phase-bridge rectifier circuits in parallel to form a 12-pulse power feeding equipment. This part of the transfer function of the filter can be indicated by an order inertia link. The filter time constant $T_{\mathrm{s}}$ can be selected as $0.0017 \mathrm{~s}$.

Design of current regulator

The control voltage $U_{i}^{*}$ is designed in the range of 0 $10 \mathrm{~V}$, the armature voltage $U_{\mathrm{d} 0}$ of the DC motor is 0 $870 \mathrm{~V}$. So the magnification coefficient of the rectifier is $K_{s}=870 / 10=87$. Considering the wave front time is $1.67 \mathrm{~ms}$, the filter time constant of the current feedback link is set at $T_{o i}=1 \mathrm{~ms}=0.001 \mathrm{~s}$

The feedback coefficient of the current loop is

$$
\beta=\frac{U_{i}^{*}}{\lambda I_{\mathrm{N}}}=\frac{10}{1.25 \times 3100}=0.00258 \mathrm{~V} / \mathrm{A}
$$

Judging from the steady state requirements, in order to get the ideal stall characteristics, we hope that the current has no static error. According to the dynamic requirements, in the actual system, the armature current system is not allowed with much overshoot during sudden action. So as to ensure the current in the dynamic process does not exceed the allowable value. To this end, the current loop should follow nature-based. I type of system should be used ${ }^{[12-13]}$. Since the current loop control object is a double inertia, to be corrected as typical system, PI type current regulator should be used apparently. The transfer function can be expressed as

$$
W_{A C R}(s)=\frac{K_{i}\left(\tau_{i} s+1\right)}{\tau_{i} s}
$$

Where $K_{i}$ is the scale factor of the current regulator; $\tau_{i}$ is ahead of the current time constant of the regulator.

As can be seen from the formula (6), the current regulator parameter $K_{i}$ and $\tau_{i}$ are still unknown. In order that the zero of regulator can be neutralized by the great time constant of the controller object, choose $\tau_{i}=T_{l}=0.185 \mathrm{~s}$, then the only one unknown parameter is the scaling factor $K_{i}$

So the typical form of the current loop is converted to

$$
K_{I}=\frac{K_{i} K_{s} \beta}{\tau_{i} R_{a}}
$$

The minimum time constant of the current loop is the sum of $T_{\sum i}$, in accordance with the small time constant approximation process, taking $T_{\sum i}=T_{s}+T_{o i}=0.0017 \mathrm{~s}+0.001 \mathrm{~s}=0.0027 \mathrm{~s}$

Depending on the required dynamic performance, the exception of the design of the current overshot is $\delta_{i} \leq 5 \%$.According to the condition, $\xi=0.707$, $K_{I} T_{\sum i}=0.5$.

So the open loop gain is designed as

$$
K_{I}=0.5 / T_{\sum i}=0.5 / 0.0027=185
$$

So the scale factor for the ACR is

$$
K_{i}=\frac{K_{I} \tau_{i} R_{a}}{K_{s} \beta}=\frac{185 \times 0.185 \times 0.01}{87 \times 0.00258}=1.525(9)
$$

Then, the current loop ACR regulator can be expressed as

$$
W_{A C R}(s)=\frac{1.525(0.185 s+1)}{0.185 s}
$$

\section{Design of speed regulator}

The feedback factor of the speed loop voltage is $\alpha=u_{N} / n_{N}=10 / 50=0.2 V . \min / r$ 
In order to achieve speed static error, so the speed open loop transfer function should consist two integral parts, so it should be designed to type II system $I_{d}$, such a system should meet the requirements of good performance for dynamic Immunity ${ }^{[14]}$. Thus, ASR PI regulator should be adopted. The transfer function is

$$
W_{A S R}(s)=\frac{K_{n}\left(\tau_{n} s+1\right)}{\tau_{n} s}
$$

The transfer function of the open-loop speed control system is

$$
W_{n}(s)=\frac{K_{N}\left(\tau_{n} s+1\right)}{s^{2}\left(T_{\sum n} s+1\right)}
$$

Where the open loop gain is

$$
K_{N}=\frac{K_{n} \alpha R_{a}}{\tau_{n} \beta C_{e} T_{m}}
$$

So the closed loop gain is

$$
K_{n}=\frac{(h+1) \beta C_{e} T_{m}}{2 h \alpha R_{a} T_{\Sigma n}}
$$

After simplified, the current loop can be regarded as a part of the speed loop; the equivalent time constant of the current loop is $1 / K_{I}$. According to the ripple size of the tachometer, the filter time constant of the speed loop can be determined as $T_{\text {on }}=0.01 \mathrm{~s}$. So the small time constant of the speed loop can be determined by

$$
T_{\sum n}=\frac{1}{K_{I}}+T_{o n}=\frac{1}{185} s+0.01 s=0.0154 s
$$

Depending on the principle of both follow resistance and immunity performance are good. $h=5$. The ahead time constant of ASR can be determined as

$\tau_{n}=h T_{\Sigma n}=5 \times 0.0154 s=0.077 s$

The closed loop gain is designed as

$$
\begin{aligned}
K_{n} & =\frac{(h+1) \beta C_{e} T_{m}}{2 h \alpha R_{a} T_{\Sigma n}} \\
& =\frac{6 \times 0.00258 \times 16.78 \times 0.0127}{2 \times 5 \times 0.2 \times 0.01 \times 0.0154}=10.71
\end{aligned}
$$

Then the speed loop controller ASR can be expressed

$$
W_{A S R}(s)=\frac{10.71(0.077 s+1)}{0.077 s}
$$

\section{SIMULATION AND RESULTS ANALYSIS}

According to the above parameters that calculated by the methods of engineering design. A specific model of the main drive speed control system is designed. The model is tested in MATLAB simulation platform. Simulation results for the drive system are shown in the following figures. Simulation curves shown in Fig. 2 are the current simulation results. The speed simulation results are shown in Fig. 3.The current loop feedback voltage $U_{i}$ simulation results are shown in Fig. 4 .The speed loop feedback voltage $U_{n}$ simulation results are shown in Fig. 5.

The simulation graphs show that at the moment the motor starts the armature current increases instantly. However, due to mechanical and electrical inertia, the speed of the motor will not grow quickly. Because the value of the input offset voltage $\Delta U_{n}$ for the speed regulator ASR is still large, so the output voltage keep the limiting value forcing the armature current remains a rapid rise. Until $I_{d} \approx I_{d m}, U_{i} \approx U_{i m}^{*}$, the growth of $I_{d}$ is suppressed by the current regulator. At the same time, ASR enters and keeps saturation. However, ACR is not saturated generally.

When the speed rises to the given value $n^{*}=n_{N}=50 \mathrm{rpm}$. The input bias of the ASR speed regulator reduces to zero. Due to the integral action, the motor is still accelerating, resulting in speed overshoot. After speed overshoot, ASR begins to withdraw from saturation. $U_{d}$ and $I_{d}$ start to decrease quickly, the speed keeps on rising as long as $I_{d}$ is larger than $I_{d l}$. When the motor starts, the current loop feedback voltage $U_{i}$ is the biggest value $12 \mathrm{~V}$, the speed closed-loop feedback voltage $U_{d}$ is the least value $0 \mathrm{~V}$, along with the speed increases, the current decreases. Until the speed reaches the maximum value, both the armature current and the current loop feedback voltage decrease to minimum value. When the speed reaches a peak, the motor begins to slow down under the load resistance, at the same time, the armature current also decreased rapidly until stable ${ }^{[15-16]}$. Finally, both the armature current and the speed reach steady state. The armature current reaches at the rated $3100 \mathrm{~A}$, the speed reaches and keeps at the rated $50 \mathrm{rpm}$.Both the current loop feedback voltage and the speed loop voltage reach steady state. 


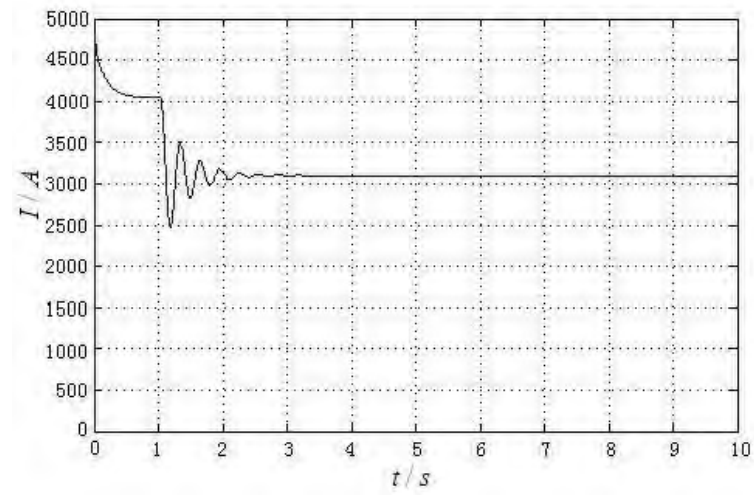

Figure 2.The curve of current simulation

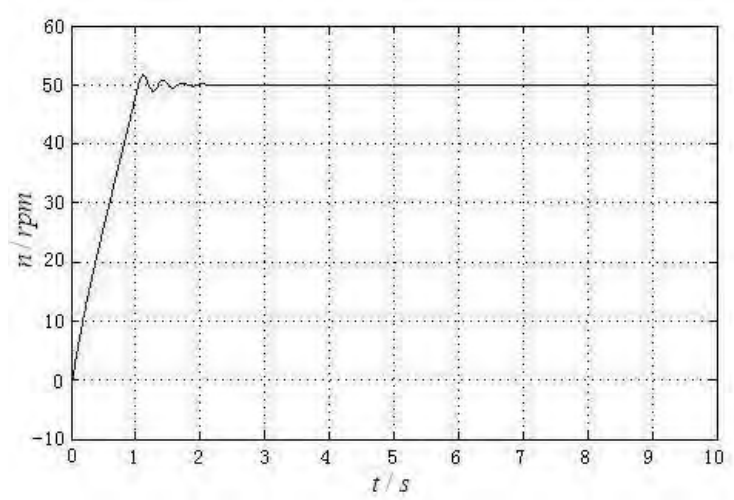

Figure 3.The curve of speed simulation

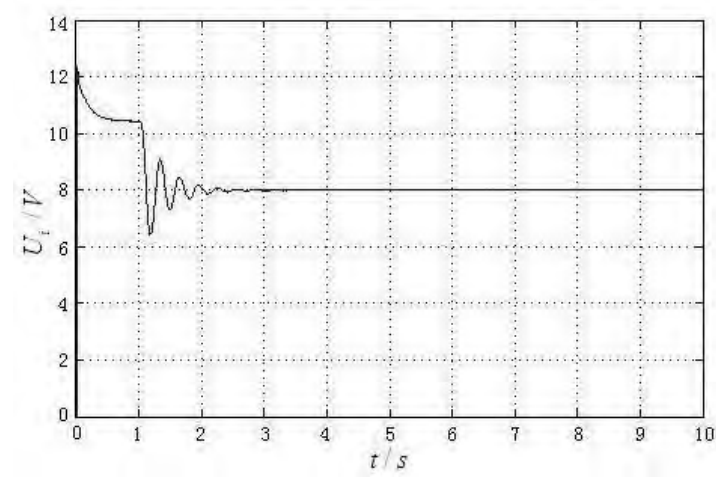

Figure 4.The curve of current loop feedback voltage simulation

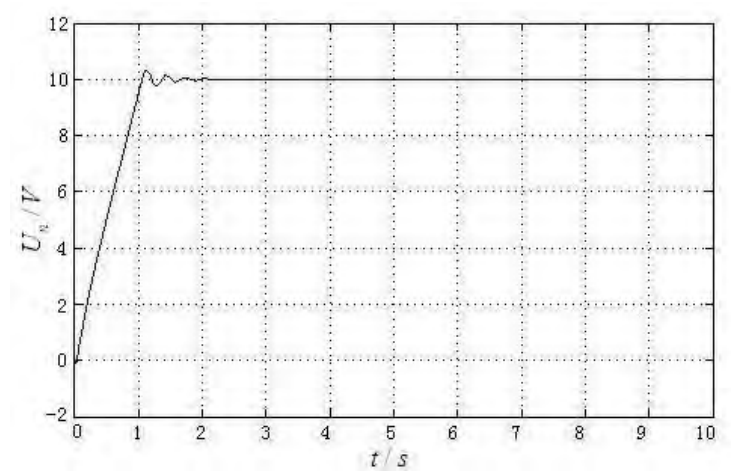

Figure 5.The curve of speed feedback voltage simulation

\section{CONCLUSIONS}

The double-loop control system designed in this paper applies to the main drive speed regulating system has a good control effect.

\section{REFERENCES}

[1] C. Bettles and M. Barnett. Sachdev.Advances in Wrought Magnesium Alloys-Fundamentals of pcocessing,properties and applications [M]. Cambridge :Woodhead PublishingLtd,2012.

[2] Mathis K, Trojanova Z, Lukac P, Cáceres CH etc. Modeling of hardening and softening processes in $\mathrm{Mg}$ alloys[J]. Journal of Alloys and Compounds,2004,378:176-179.

[3] Dreyer CE, Chiu WV, Wagoner RH and Agnew SR. Formability of a more randomly textured magnesium alloy sheet: Application of an improved warm sheet formability test[J]. Journal of Materials Processing Technology. 2010,210: 37-47.

[4] Staroselsky A and Anand L. A constitutive model for hcp materials deforming by slip and twinning: application to magnesium alloy AZ31B[J]. International Journal of Plasticity,2003,19: 1843-1864.

[5] Wang Y, Chen LQ, Liu ZK and Mathaudhu SN. First-principles calculations of twinboundary and stacking-fault energies in magnesium[J]. Scripta Materialia,2010,62: 646-649.

[6] Sun Yin-kang.Cold rolled strip mill model and control[M].Beijing: Metallurgical Industry Press,2010.1.(Chinese).

[7] Yong-jiang ZHENG, Author Vitae,Guang-xian SHEN. Spatial Vibration and Its Numerical Analytical Method of Four-high Rolling Mills [J].Journal of Tron and Stell Research, Internal ,2004 ,21(9):837-843.

[8] Mohamed S. Zaky.A self-tuning PI controller for the speed control of electrical motor drives[J]. Electric Power Systems Research ,2015,119,unpublished.

[9] Li Heng, and Han Xiang-feng.Matlab simulation of fuzzy PID Double Loop DC Motor Control System Based[J]. Coal Mine Modernization,2009,9(10):66-68.[Chinese]

[10] P. Krishnamurthy, F. Khorrami .Voltage-fed permanent-magnet stepper motorcontrol via position-only feedback[J].Control Theory Press,Aug.2004 ,pp499-510,doi:10.1049/ip-cta:20040622.

[11] F. Betin, M. Deloizy, C. Goeldel.Closed loop control of stepping motor drive:comparison between PID control, self tuning regulation and fuzzy logic control[J].Eur.Power Electron,1991,8(12):33-39.

[12] W. Kim, C. Yang, C.C. Chung.Design and implementation of simplefield-oriented control for permanent magnet stepper motors without DQ trans-formation[J]. IEEE, Magnetics Society,Press, Oct. 2011,pp4231-4234,doi: 10.1109/TMAG.2011.2157956.

[13] Chen D and Segorg DE. PI/PID controller design based on direct synthesis and disturbance rejection[J]. Industrial \& Engineering Chemostry Research, 2002,41(19):4807-22

[14] Cai YH, Qi RY, Cai J, Deng ZQ. Online modeling for switched reluctance motor using radial basis function neural network and its experimental validation $[\mathrm{J}]$. Acta Aeronautica et Astronautica Sinica ,2012,33(4): 705-14.(Chinese)

[15] Chen Bo-shi.Electric Drive Automatic Control System - Motion Control System[M].Beijing: Machinery Industry Press,2003.(Chinese)

[16] Zhang Chong-wei.Motion Control System[M].Wuhan:Wuhan University of Technology Press,2002. (Chinese) 